\title{
Fracture failure analysis of the pump shaft
}

\author{
Jiang Chengjun ${ }^{1 a^{*}}$, Tao Kai ${ }^{2 b}$, Wang Jifeng ${ }^{1 \mathrm{c}}$ and Wang Wei ${ }^{1 \mathrm{~d}}$ \\ ${ }^{1}$ Shanghai Institute of Special Equipment Inspection \& Technical Research, Putuo, Shanghai, China \\ ${ }^{2}$ Shanghai Morimatsu Pressure Vessel Co., Ltd, Pudong, Shanghai, China
}

\begin{abstract}
The failure reasons of the circulating pump shaft in the upper section of the quench tower were analyzed by means of chemical composition analysis, macroscopic observation, metallographic examination and fracture section analysis. The analysis result shows that the calcium-silicate inclusions in the surface of the pump shaft cause the microcracks and the parallel fatigue sources, which leads to the fatigue cracks propagation under alternating load and finally the shaft is fatigue fractured.
\end{abstract}

\section{Induction}

A sudden abnormal sound was detected in the circulating pump with the type of $\mathrm{p}-107 \mathrm{~S}$ in the upper section of the quench tower of an acrylonitrile unit in Shanghai in 2019, and then the circulating pump was stopped and lift for inspection. The pump shaft was found fractured, and other parts were basically intact. The fractured part of the pump shaft was at the keyway of the shaft shoulder, where the structure of the pump shaft was discontinuous, as shown in Fig.1.

The circulating pump has been in use for nearly 6 years. The pump was a single-stage double-suction centrifugal pump with the flow rate of $10,000 \mathrm{~m}^{3} / \mathrm{h}$, the head of delivery of $62 \mathrm{~m}$, the power of $2100 \mathrm{~kW}$, and the speed of 590 $/ \mathrm{min}$. The sealing type was packing seal, and the bearing lubrication type was grease lubrication. The impeller was the type of closed double-suction, and the coupling was the type of laminating coupling. The design material of the pump shaft was the austenitic steel forging of $06 \mathrm{Cr} 17 \mathrm{Ni12Mo} 2 \mathrm{Ti}$ (according to $\mathrm{NB} / \mathrm{T}$ 47010-2010 'Stainless and heat-resisting steel forgings for pressure equipments'). The diameter of the pump shaft was $215 \mathrm{~mm}$, and the keyway width was $10 \mathrm{~mm}$.

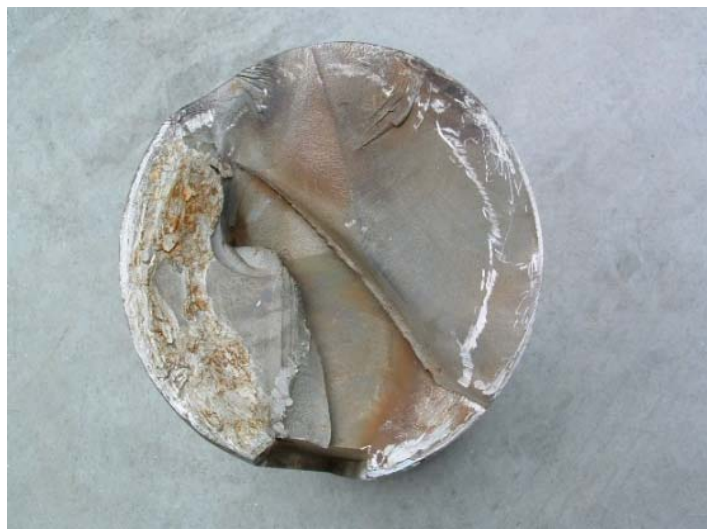

Fig.1 The fractured circulating pump shaft

\section{Chemical composition analysis of the pump shaft}

In order to confirm whether the material of the pump shaft is consistent with the original design, the chemical composition of the shaft material is analyzed, as shown in Tab.1.

The test result shows that the chemical composition of the fractured pump shaft is approximately consistent with the standard recommended value range. The specific material brand shall be austenitic stainless steel forging of $06 \mathrm{Cr} 17 \mathrm{Ni} 12 \mathrm{Mo} 2 \mathrm{Ti}$, which is consistent with the original design material[1]. In addition to the good corrosion resistance of this material, the comprehensive mechanical properties of this material are better. It has the good plasticity and toughness. However, the material contains a lot of silicon (1.27\%), which exceeds the standard upper limit, while a high content of silicon will reduce the toughness and plasticity of the material, and

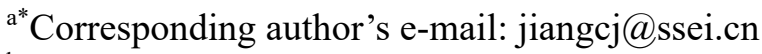

bemail: taokai@morimatsu.cn, email: wangjf@ssei.cn, email: wangwei@ssei.cn
} 
adverse to the weldability and easy to cause the coldbrittleness[2].

Tab.1 Chemical composition analysis of the fractured pump shaft $100 \%$

\begin{tabular}{|c|c|c|c|}
\hline Elements & Standard recommended & Test value & \\
\hline $\mathrm{C}$ & $\leqslant 0.08$ & 0.07 & pump shaft \\
\hline
\end{tabular}

As shown in Fig.2(a), the fractured site of the pump shaft is located below the keyway of the combiner at the upper end of the pump shaft. The bottom of the pump shaft is machined thread, which is used to fix the axial position. The fractured section is at the keyway arc junction far away the bottom thread.

\begin{tabular}{|c|c|c|}
\hline Mo & $16.00 \sim 18.00$ & 17.11 \\
\hline $\mathrm{Ni}$ & $2.00 \sim 3.00$ & 2.01 \\
\hline
\end{tabular}

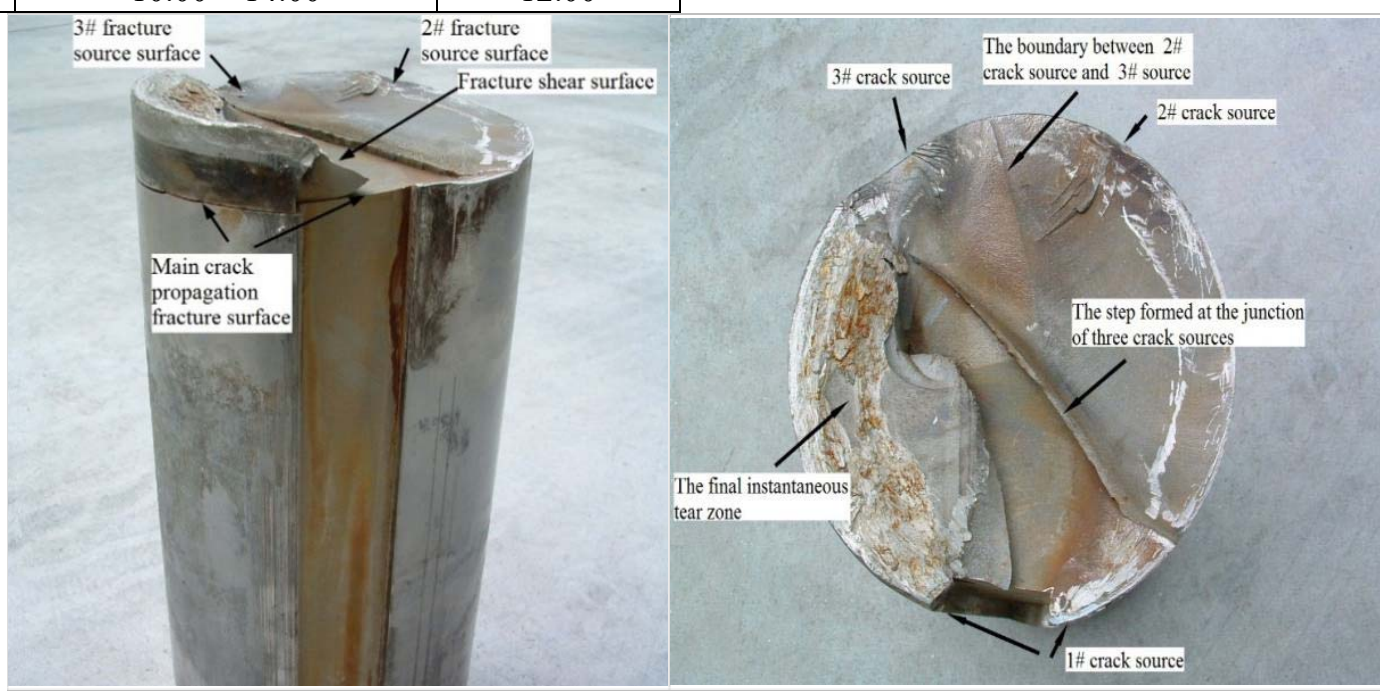

(a)

(b)

Fig.2 Macromorphology of the pump shaft fracture section

As shown in Fig.2(b), the whole fracture is divided into two main areas, one is the relatively smooth crack growth zone and the final uneven fracture zone. In the smooth crack growth zone, there are three parts where the black arrows point according to the crack growth steps. The parts are carefully observed that $1 \#$ crack is at the junction of the outer surface of the shaft and the machined surface of the keyway; $2 \#$ crack and $3 \#$ crack are at the axial fracture section. These three parts are the formed crack initiation parts as shown in Fig.2(b). The whole smooth crack propagation zone can be observed that the three crack sources are in different cross sections. Therefore, three steps are formed when the crack sources expand to the junctions. The middle step is the step formed by the interface of the three crack sources, while the lighter step on the fracture section is the step at the junction of $2 \#$ crack source and $3 \#$ crack source. The third step is the step formed by the crack growth zone and the final fracture zone, and the step finally tears rapidly in the form of shear layer at an angle of $45^{\circ}$.

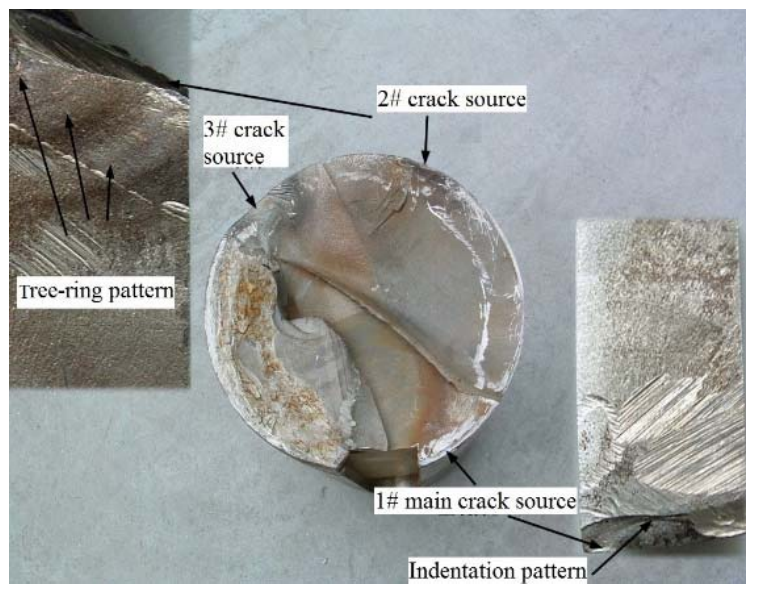

Fig.3 Partial appearance of the crack sources of the pump shaft

The features and patterns are found on the fracture section, such as the tree-rings and the indentation marks, which indicates that the fracture is a typical fatigue fracture, as shown in Fig.3. The characteristic of the features and patterns is often formed during circulating operation by the fatigue fracture propagation. When the friction between two matching fracture sections is very intense in the process of circulating operation, the mechanical polishing marks will appear in the smooth area, especially near the source area. In addition, the 
surface of the fatigue crack growth zone is dark brown in color, while the surface of the final fracture zone is the fresh metallic luster in color in Fig.3[3]. The obvious difference in color between the fatigue crack growth zone and the final fracture zone is because the fatigue crack growth zone takes longer to form than the final fracture zone. The fatigue crack source is formed on the surface, and then the fatigue crack growth is connected with the external environment, so the surface of the fatigue crack growth zone is dark brown due to oxidation or corrosion, while the final fracture zone usually tears quickly and appears the color of metallic luster.

Through analysis of the fracture morphology characteristics of the pump shaft, it can be confirmed that the reason of the pump shaft fracture is the fatigue fracture failure caused by alternating load.

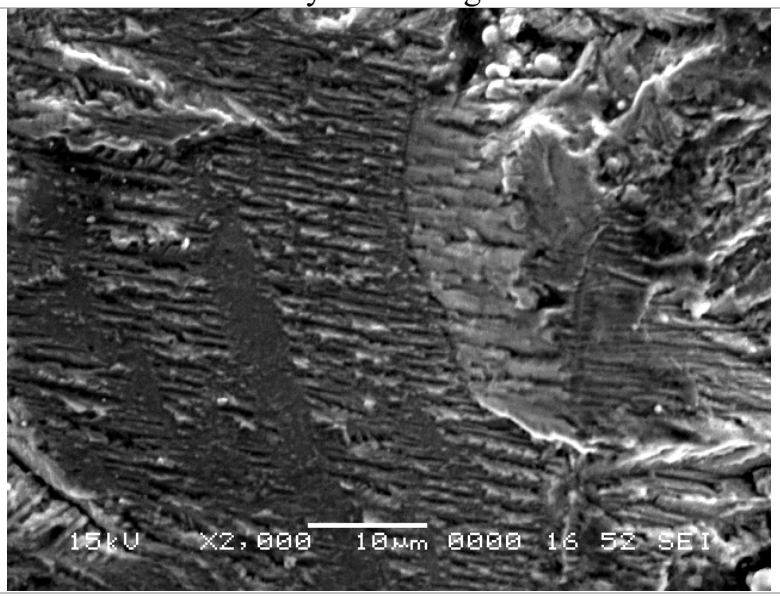

Fig.4 Micromorphology of the shaft fracture sections

\section{Analysis of the fractured influencing factors of the pump shaft}

According to the macromorphology and micromorphology characteristics of the pump shaft fracture section, it can be confirmed that the pump shaft fracture is caused by fatigue failure. So the question is whether the pump shaft had operated for the whole design fatigue life. According to the technical parameters of the circulating pump, the expected service life of the pump shaft is about 20 years as same as the quench tower. Then it is essential to figure out what factors accelerate the fatigue fracture of the pump shaft. According to the specific characteristics of the pump shaft, the following factors need to be analyzed:

(1) Whether the material structure distribution of the pump shaft and the heat treatment process are appropriate;

(2) Whether the state of material crack sources of the pump shaft surface is normal;

\section{Analysis of the micromorphology characteristics of the shaft fracture section}

The micromorphology pictures at 2000 and 3000 magnification is taken in the shaft fracture section, as shown in Fig.4. Fatigue striations are observed parallel to each other with equal spacing in the pictures, which is the most prominent feature of the fatigue fracture[3]. It can be judged that the striations belongs to the toughness fatigue striations. The crack propagation direction is the vertical direction of the striations.

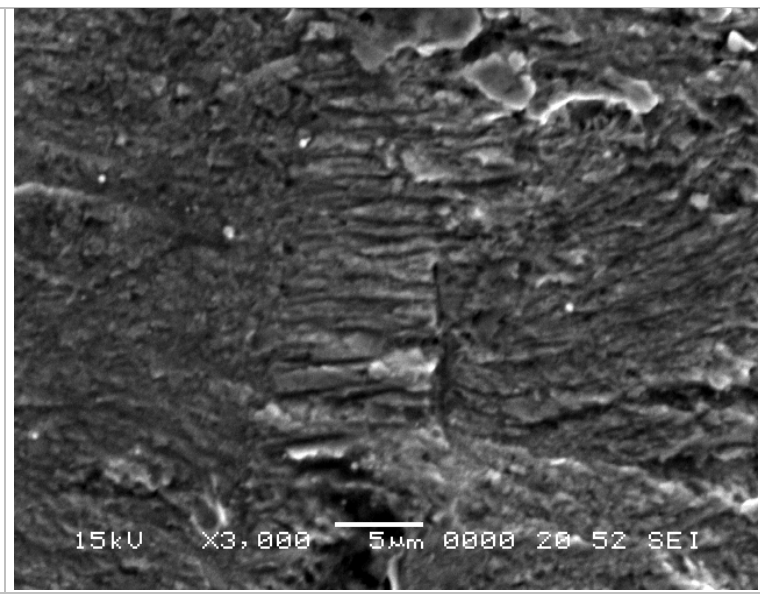

(3) Whether the processing state of the pump shaft surface at the keyway site is intact.

\subsection{Analysis of the material structure distribution of the pump shaft}

The metallographic structures was analyzed on the fracture sections of $1 \#$ crack source and $2 \#$ crack source, as shown in Fig.5.The material structure of the pump shaft are austenite plus strip ferrite, and the gray strip ferrite with different lengths is distributed in the white austenite matrix. There are twin crystals in the austenite matrix, indicating that the material has been processed by solid solution treatment[4]. In general, the normal austenite matrix contains a very small amount of ferrite, which is commonly in a single austenite phase or a phase of austenite plus carbide precipitation. A lot of ferrite was precipitated in the austenite matrix this time, indicating that the heat treatment temperature is too high or the heat treatment time is too long. 

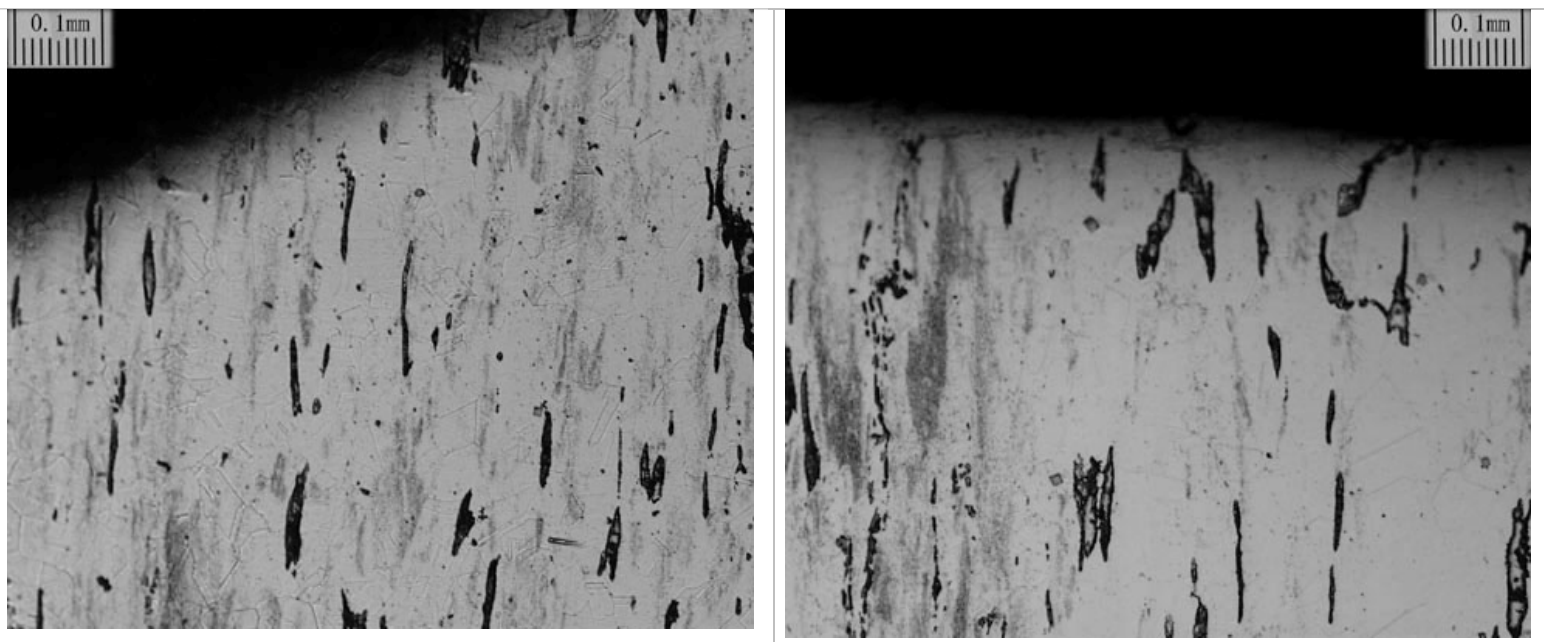

Fig. 5 Metallographic structure pictures of the fracture sections of 1 \# (the left picture) \& 2 \# (the right picture) crack sources $\times 100$

Ferrite precipitation in austenite matrix can generally prevent the austenite grains coarsening, improve the yield point of the material and reduce the tendency of intercrystalline corrosion and stress corrosion. The disadvantage is that it promotes the transition from $\mathrm{Cr}$ in ferrite to $\sigma$-brittle phase and the formation of $\sigma$-phase, and increases the brittleness of materials and the tendency of point corrosion[5]. According to the metallographic structure photos, it can be observed that the strip ferrite precipitation is mainly distributed along the axial direction of the pump shaft, and the fracture sections of the pump shaft is perpendicular to the distribution direction of strip ferrite. Therefore, the ferrite contained in the material can be considered taking little influence on the fatigue fracture of the pump shaft.

\subsection{Analysis of state factors at the crack source of the pump shaft}

(1) The micromorphology of the fracture section at $1 \#$ fracture source of the pump shaft

The micromorphology of $1 \#$ crack source at the keyway of the shaft is chosen to analyze by Scanning

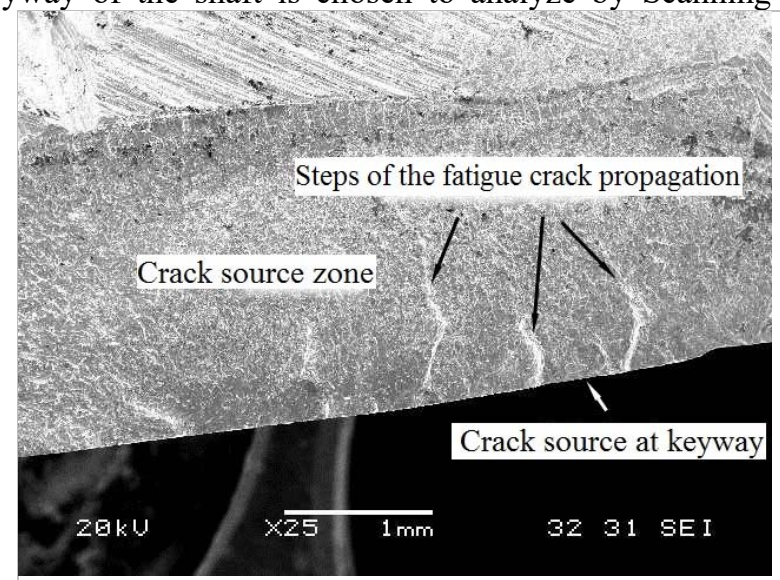

(a)
Electron Microscope (SEM), as shown in Fig.6(a). There is no induction factor of the pitting corrosion at the edge of the crack source, and the steps of the fatigue crack propagation are clearly visible.

The micromorphology of the crack source at the keyway of the shaft magnified by 1200 times locally is shown in Fig.6(b). The crack at the edge of the crack source can be observed containing a lot of inclusions, which are mainly composed of $\mathrm{O}, \mathrm{C}, \mathrm{Si}, \mathrm{Ca}$ and $\mathrm{Fe}$ by elemental energy spectrum analysis as shown in Fig.7. The content of $\mathrm{Ca}$ was $3.11 \%$, Fe was $26.9 \%$, Si was $1.09 \%$. Therefore, these inclusions are confirmed as calcium-silicate $(\mathrm{CaO} . \mathrm{SiO} 2)$. In the solidification process of steel material, liquid calcium-silicate has no time to crystallize due to the fast cooling speed of steel, and thus the calcium-silicate is retained in the steel in the form of inclusions at last. These calcium-silicate inclusions will not be deformed and brittle at room temperature, and keep their original shape[6]. According to GB10561-89" Steel-determination of content of non-metallic inclusions: Micrographic method using standard diagrams ", the calcium-silicate inclusions of the material shall be rated as 1.5 .

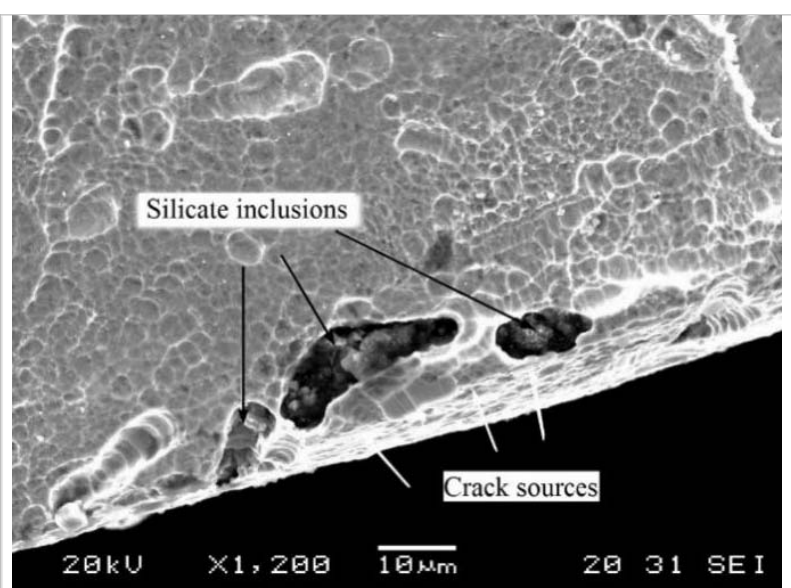

(b)

$\times 1200$

Fig.6 The fracture section pictures of $1 \#$ crack source at the keyway 
At the same time, it can be observed in Fig.6(b) that the fracture section at the crack origin is generally dimpled and ductile as same as the characteristic of the ductile fracture. This indicates that the austenitic material has good toughness and plasticity. It is certain that the inclusions are the source of crack initiation according to Fig.6(b). The microstructure of precipitated phase of strip ferrite in austenite matrix is shown in Fig.8. There is a

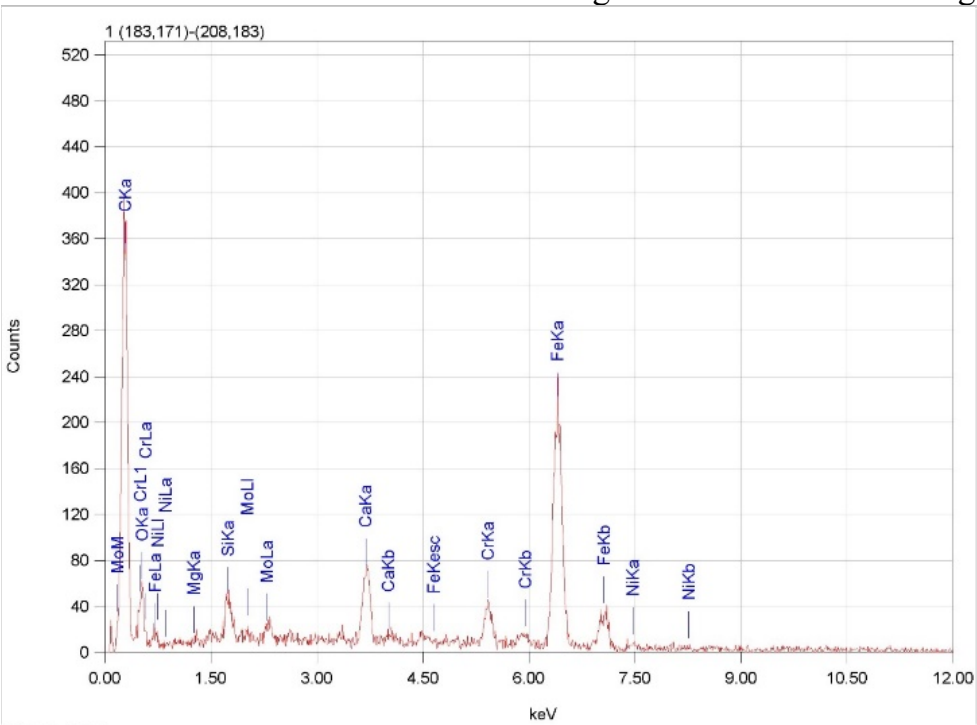

Fig.7 Power spectrum analysis of the crack surface inclusions at the keyway Fig.8 Precipitated phase of ferrite in austenite matrix of the fracture section close relationship between formation of the fatigue crack sources and the plastic deformation process, because the steel metal which is easy to deform will generate great stress when it flows around the inclusions which are difficult to deform. As a result, the connection of the steel metal and the inclusions will fracture and microcracks appear which will become the crack source of fatigue crack propagation.

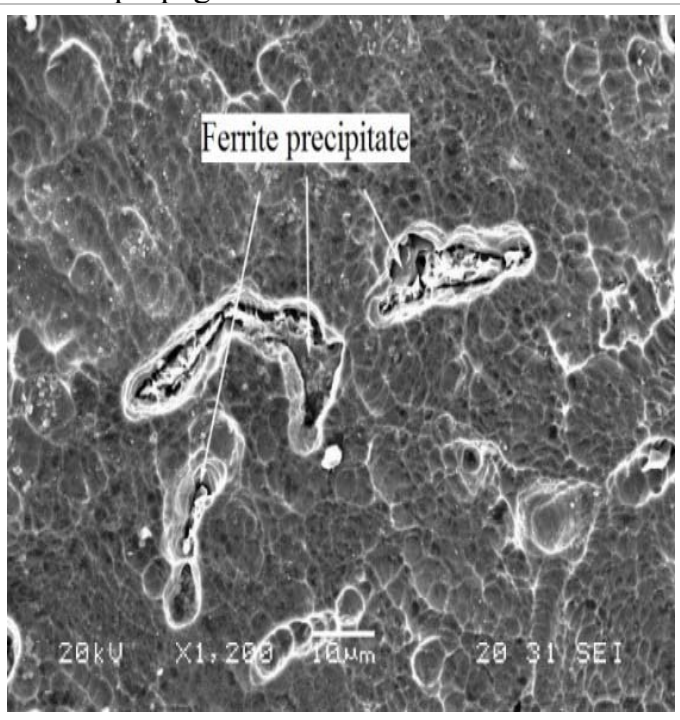

According to the fracture analysis of the microstructure characteristics of the shaft crack sources, inducing factors of the fatigue crack source was a lot of calcium-silicate inclusions in the material surface, and surface plastic deformation is happened on the pump shaft by loads, so that the interface deformation of the inclusions and the surrounding plastic flow of the material mismatch, resulting in the microcracks at the fatigue crack sources [7].

(2) Analysis of the outside surface state of the shaft

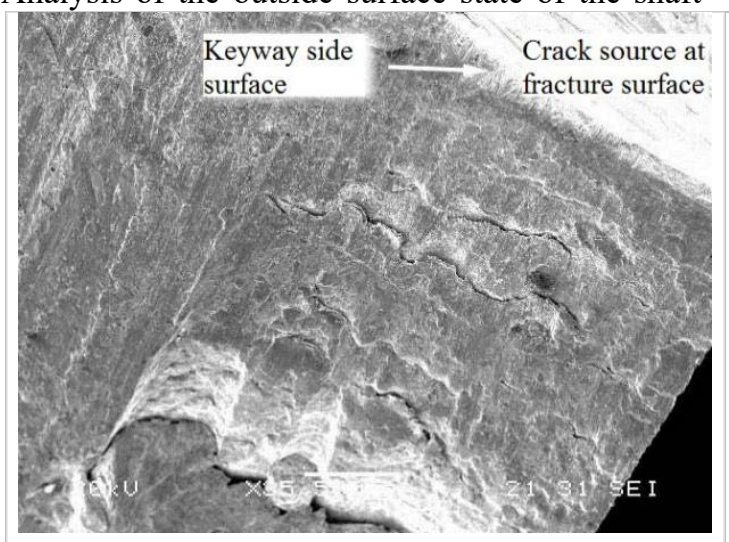

(a) $\times 35$ keyway

The outside surface state of the vertical axis of the fracture section at the keyway of pump shaft is shown in Fig.9. There are several parallel transverse microcracks on the outside surface tightly below the main fracture section, accompanied by the characteristics of deformation damage. Also there are calcium-silicate inclusions between these microcracks, and the stripe structures distributed along the axial direction on the surface are mainly precipitates of the ferrite phase.

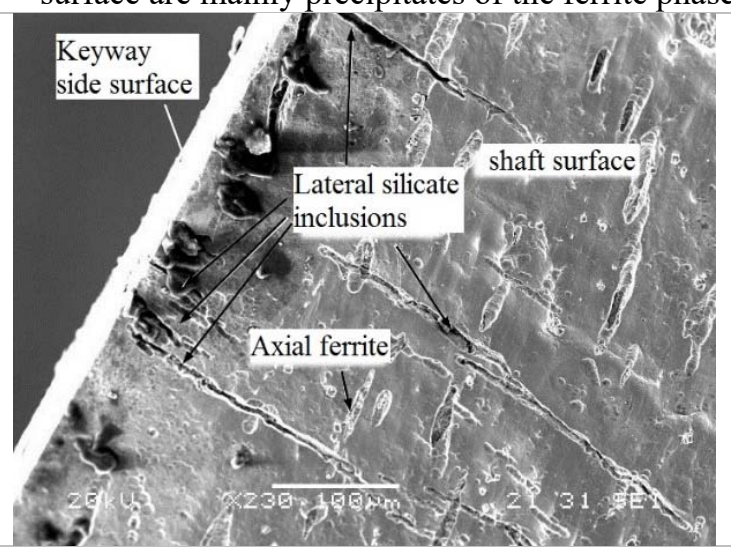

(b)

Fig.9 Outside surface state at the keyway of the shaft

The outside surface state of $1 \#$ crack source below the keyway is shown in Fig.10. There are obvious slip lines of plastic deformation on the outer surface of the shaft, and the outer surface of the middle part is damaged due to plastic deformation, which leads to microcracks on the outer surface.

The outside surface state of $2 \#$ crack source also has the characteristics of plastic deformation and local surface damage, which is similar to the outside surface state of 1\# crack source, as shown in Fig.11. 


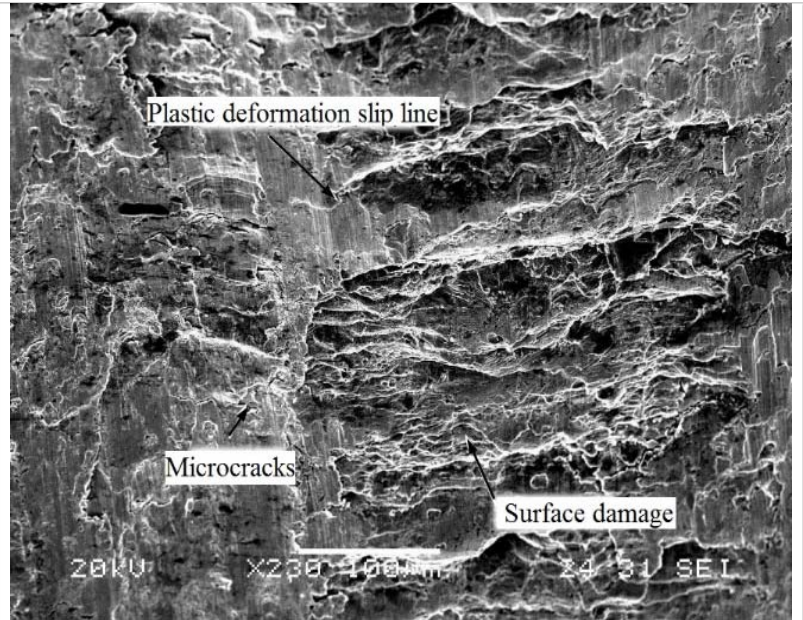

Fig.10 Outside surface state of $1 \#$ crack source below the keyway $\times 230$

According to the above analysis, it can verify that the fatigue crack sources are caused by calcium-silicate inclusions and then several parallel crack sources on different loading surfaces forms, which will cause fatigue cracks propagation under alternating loading conditions.

\subsection{Machined surface state analysis of the keyway}

According to the macromorphology of the machined surface of the keyway shown in Fig.12, the machined surface of the keyway side sections and the circular arc area is in normal condition, but the characteristics of local deformation damage on the outside surface near $1 \#$ crack source can be observed, which is consistent with the previous analysis.

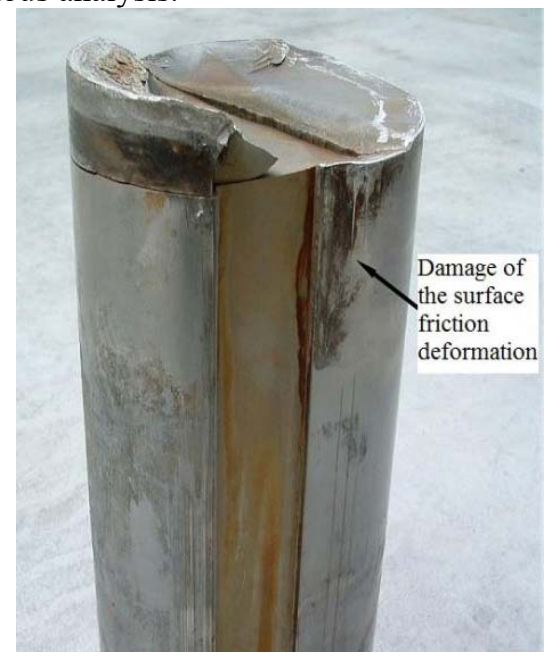

Fig.12 Outside surface macromorphology of the keyway

\section{Conclusion and recommendation for replacement}

Based on the above tests, the analysis conclusion is that the fracture failure of the pump shaft is the mutual friction deformation damage of the outside keyway surface and the pump shaft coupling, and then the large

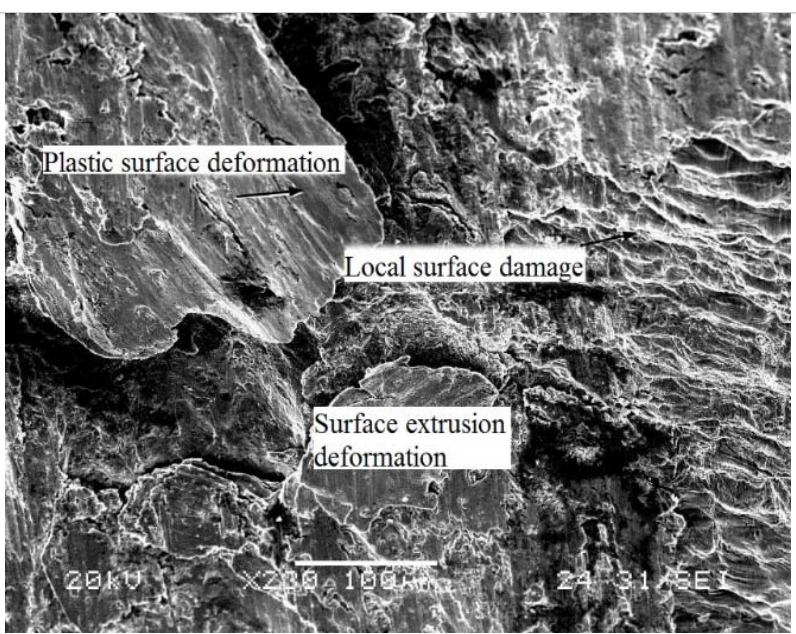

Fig.11 Outside surface state of $2 \#$ crack source $\times 230$

plastic flow deformation is happened at the shaft surface, but there are much non-deforming calcium-silicate inclusions distributed on the shaft surface inducing the fatigue cracks initiation on the interface, and the fatigue cracks propagation occurs by alternating load.

According to the above analysis, the corresponding improvement measures can be taken:

(1) When installing the pump shaft, forced assembly shall be prohibited according to the technical regulations to avoid surface damage at the keyway of the shaft. The outside surface of the keyway must be kept intact after the manufacture and installation of the pump shaft.

(2) The chemical compositions of the pump shaft material shall be strictly controlled in the standard range, especially the elements of sulfur, phosphorus, silicon. In addition, the calcium-silicate inclusions in the pump shaft material must be well controlled.

\section{References}

1. Zhang X.X., Qin X.Z., Zhang Y. et al. (2010) NB/T 47010-2010 'Stainless and heat-resisting steel forgings for pressure equipments'. China Standards Press, Beijing.

2. Li C.S., Huang D.B.. (2007)Materials manual of Mechanical engineering. Electronic Industry Press, Beijing.

3. He D.F.. (1990)Failure analysis and fault prevention. Metallurgy Industry Press, Beijing.

4. Li T.H.. (2006)Metallographic map of metallic Materials. China Machine Press, Beijing.

5. Cui Y.X.. (1998) Fracture analysis of metal. Harbin Institute of Technology Press, Harbin.

6. A. M. Lancha, J. Lapeña, M. Serrano, I. Gorrochategui. Metallurgical failure analysis of a BWR recirculation pump shaft[J]. Engineering Failure Analysis. 2000, 7(5):333-346

7. Wang D.L.. (1988)Failure analysis of shaft and fastener. China Machine Press, Beijing. 